\title{
The maximum Waterway Dimensions by Channel Regulation of Duliu
}

\author{
River \\ Wanli LIU ${ }^{1, a}$, Yude ZHU ${ }^{1}$, Kejun PING ${ }^{1}$, Ying $\mathrm{LU}^{2}$ and Fei HAN ${ }^{2}$ \\ ${ }^{1}$ Key Laboratory of Engineering Sediment of Ministry of Communications, Tianjin Research Institute \\ for Water Transport Engineering, Tianjin 300456, China \\ atjtgliuwanli@163.com \\ ${ }^{2}$ Changjiang Waterway Bureau, Wuhan 430010, China
}

Keywords: research Methods; waterway dimension; channel regulation

\begin{abstract}
In the past, waterway regulation generally proposed optimized project scheme and the corresponding regulation measures according to the waterway dimension of the design requirements, upon the requirements of satisfaction of the standard waterway dimension. However, whether the dimension is the reasonable limit dimension was not involved. Depending on the regulation project of the northern waterway of the access to the sea of southwest water transport, this article researches on the problem of the waterway dimension which the long stream segment regulation of Duliu River may achieve. Through the research, it proposes the computation methods for the maximum navigable dimension.
\end{abstract}

\section{The Concept of Waterway Dimension}

The design waterway dimension generally refers to the navigation depth, navigation width and curvature radius which are calculated with the lowest design navigation water level. Ascertaining the design waterway dimension is a key link of planning and design of inland river waterway project. Its reasonableness influences indirectly the success or failure of regulation project, efficiency and development of water transport business. Currently, there are five methods to ascertain the waterway dimension domestically. They are respectively the economic waterway dimension, ascertaining the waterway dimension with selected ships, inland river navigation standard, waterway dimension which the regulation may achieve and method combining canalization and regulation. The waterway dimension which the regulation may achieve needs detailed materials of terrain, geology, hydrology, sediments and riverbed composition of the local rivers. The possibly potential reasonable limit dimension of the local river can only be ascertained through river evolution analysis and mathematical and physical model argument.

\section{Economic Waterway Dimension}

The economic waterway dimension places particular emphasis on economic calculation. It generally finds the transportation cost per ton kilometer of the navigable ship and the investment of the ship and waterway per ton kilometer under different waterway dimensions and draws the curve. And take the dimension corresponding to the minimum value of the sum of them (transportation cost and investment cost) as the design waterway dimension, which is called economic waterway dimension. This kind of dimension is under the precondition that the river course navigation potential has relatively large surplus. The flow quantity of Duliu River is small in the dry season which lasts long, and the waterway dimension combination is limited. Therefore, this method is not suitable for optimizing the waterway dimension of Duliu River. 


\section{Ascertaining the Waterway Dimension with Selected Ships}

Ascertain the formula for design waterway dimension according to the ships. Thus,

1) Navigation depth

$$
\mathrm{t}_{\mathrm{c}}=\mathrm{t}_{0}+\Delta \mathrm{t}_{\mathrm{c}}
$$

In the formula: $\mathrm{t}_{\mathrm{c}} \longrightarrow$ design navigation depth $(\mathrm{m}) ; \mathrm{t}_{0}-$ load draught of the ship; $\Delta \mathrm{t}_{\mathrm{c}}-$ underkeel clearance $(\mathrm{m})$

The bottom of the mountain area river is uneven. The underkeel clearance should have been determined leniently. However, the water depth is very small, and there will be few navigation depth, if the underkeel clearance is lenient. Therefore, it generally takes the load draught as the design navigation depth, and allows load shedding of the ship at design water level. The actual draught will be controlled by the navigation departments or the mariners.

2) The navigation width

$$
\begin{aligned}
& b_{c}=b_{F u}+b_{F d}+2 d+c \\
& b_{c}^{\prime}=b_{F}+2 d
\end{aligned}
$$

In the formula:

$\mathrm{b}_{\mathrm{c}}$ - design navigation width of the two-way navigation channel $(\mathrm{m})$;

$b_{c}^{\prime}$ design navigation width of the single-way navigation channel $(\mathrm{m})$;

$\mathrm{b}_{\mathrm{Fu}}-$ upwards track belt width $(\mathrm{m})$;

$\mathrm{b}_{\mathrm{Fd}}$ - downwards track belt width (m);

$\mathrm{d}$ - the safe distance between the track belt and the navigation channel edge $(\mathrm{m})$, set $d=\frac{1}{4} b_{F}$;

$\mathrm{c}$ - the safe distance between the track belts of two fleets of ships(m), set $c=\frac{1}{2} b_{F}$.

In the formula:

$$
\mathrm{b}_{\mathrm{F}}=\mathrm{L} \sin \alpha+\mathrm{b} \omega \mathrm{s} \alpha
$$

$\mathrm{b}_{\mathrm{F}}-$ upwards and downwards track belt width $(\mathrm{m}) ; \mathrm{L}-$ upwards and downwards ship length (m);

b- upwards and downwards ship width $(\mathrm{m}) ; \mathrm{a}-$ the drift angle of the upwards and downwards ships are set to be $3^{\circ}$ for straight line navigation channel.

Assume that the data of the upwards and downwards ships are the same and the formulas (1 2) can be simplified to be:

$$
\begin{aligned}
& b_{c}=3(L \sin \alpha+b \cos \alpha) \\
& b_{c}^{\prime}=1.5(L \sin \alpha+b \cos \alpha)
\end{aligned}
$$

Ascertaining of the design navigation width of curve waterway is relatively complicated, which is researched at home and abroad. The goal is emphasized on the drift angle and track belt width when the ship makes a turn. As long as the drift angle is got, the above-mentioned formulas for straight line navigation channel can be used for calculation. To increase the straight line design navigation width to the design navigation width at the curve, transition section needs to be set, which is generally no less than the ship length.

There are many factors influencing the drift angle, such as bending radius, central angle of the curve, flow velocity and navigation speed, water depth, characteristics of the ships and etc. Currently, there is no mature computation method. Tab. 1 is the measured data from relevant scientific research and design departments of our country.

The above-mentioned computation formulas for design navigation width mainly aims at research on the plain and hill rivers and are not applicable to the towing fleet. The flow of the mountain area rivers is turbulent and it is not easy to control the hull. The factors influencing the drift angle are even more. The above mentioned formulas are for reference only. Generally, it is computed in accordance with two-way navigation channel. Actually, people has a tacit agreement that not carry out contrasting navigation on shoals, in order to ensure that the navigation width has relatively much surplus and emergency measures can be carried out when accident occurs. 
3) Bending Radius

\begin{tabular}{|c|c|c|c|c|c|c|c|c|}
\hline$\frac{R}{L}$ & 2 & 2.5 & 3 & 3.5 & 4 & 4.5 & 5 & 6 \\
\hline Real ship test & $28^{\circ} 35^{\circ}$ & $24^{2}-29^{\circ}$ & $21^{\circ} 25^{\circ}$ & $18^{\circ}-22^{\circ}$ & $16^{2}-20^{\circ}$ & $14^{2} 18^{\circ}$ & $13^{2} 17^{\circ}$ & $11^{2} 15^{\circ}$ \\
\hline Ship model test & & $16^{2}-30^{\circ}$ & $14^{2}-25^{\circ}$ & $13^{\circ}-22^{\circ}$ & $12^{\circ}-20^{\circ}$ & $11^{2} 19^{\circ}$ & $10^{2} 17^{\circ}$ & $9^{\circ} 15^{\circ}$ \\
\hline
\end{tabular}

The bending radius and the navigation width should be considered collectively. When it is difficult to ensure the navigation width, try to increase the bending radius for remediation. When it is difficult to ensure the bending radius, increase the navigation width for remediation. It should be avoided that the two items are both of lower limit values.

\section{Inland River Navigation Standard}

Ascertain the waterway dimension according to the latest "Inland River Navigation Standard" (GB50139-2004) issued in 2004. Tab.2 lists the waterway dimensions of the natural and canalized rivers under Level IV.

Tab.2 Waterway Dimensions of the Natural and Canalized Rivers

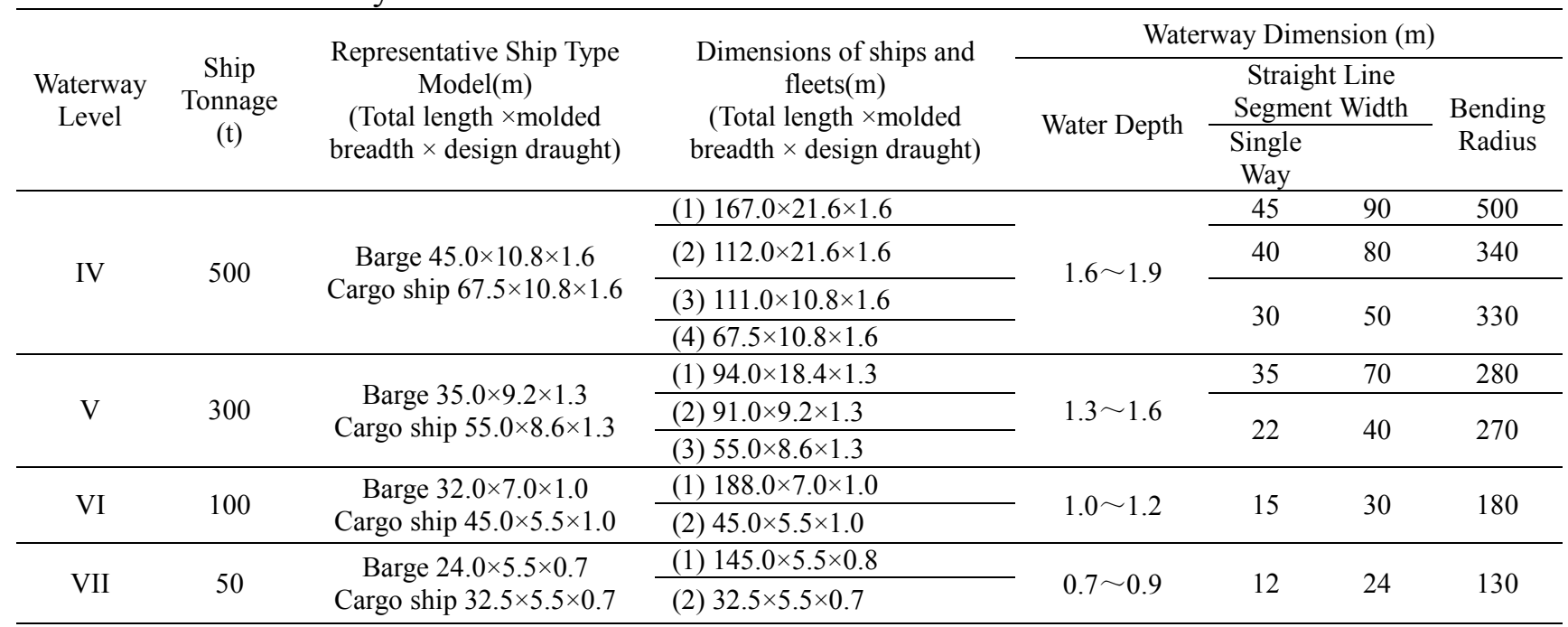

The above-mentioned domestic ascertaining methods of waterway dimension show that, the waterway dimension takes the waterway levels which the ship type and ship dimension may achieve as the major objects in consideration, and the navigation potential of the river course is not exploited to the hilt. In fact, in respect of the medium and small rivers in mountain areas of our country, the waterway dimension which the rivers may achieve through regulation determines the improvement of ship type. Therefore, exploiting the navigation potential of the river course to the hilt and seeking the maximum waterway dimension which the natural rivers may achieve through regulation are of great significance for guiding the improvement of passing capacity of long stream segment waterway.

This research focuses on the long stream segment of Duliu River and seeks for the simple and effective method for the maximum waterway dimension which the similar natural rivers in mountain area may achieve through regulation.

2. The Research Status of the Maximum Navigation Dimension At Home and Abroad

Overseas, in respect of researches on the similar problems, the former Soviet Union had proposed the concept of waterpower admissible water depth, combining with the problem of channel dredging. Actually, it is basically the same to the concept of the limit waterway dimension which the natural stream segments achieve through regulation.

America's research on the optimized waterway dimension. In America, the cost on 
architectures and maintenance of waterway trenching is generally the largest expenditure in the waterway project. Therefore, designing the optimized waterway dimension is indispensable. It can achieve the optimized efficiency/expenditure proportion. The American engineer troops use ship simulator to assist measurement of the optimized waterway dimension. Such simulator can reproduce the influences of wind, wave, and tide on the ships and give safe, economic and effective waterway dimension.

At home, on the basis of concluding the experience of domestic waterway regulation, Liu Shulun has proposed the estimation formula for the waterway water depth which the long stream segment of natural rivers can achieve after regulation, and used it in the waterway planning stage.

$$
H=K_{1} \times K_{2} \times Q^{0.312} \times J^{-0.156}
$$

In the formula:

$H$ - the minimum water depth of the waterway after regulation (m);

$Q$ - the flow quantity $\left(\mathrm{m}^{3} / \mathrm{s}\right)$ corresponding to the lowest navigation water level (design water level);

$\mathrm{J}$ - the water surface slope of the regulation stream segment in the dry season;

$K_{1}$ - waterway characteristic coefficient, for stable and good waterway, $K_{1}=0.065 \sim 0.08$; for understable waterway, $K_{1}=0.05 \sim 0.064$;

$\mathrm{K}_{2}$ - waterway width correction coefficient, $K_{2}=0.95 \sim 1.05 ; \mathrm{K}_{2}$ is generally set to be 1.0.

On the basis of concluding the experiences of stone shoal regulations of rivers in mountain areas of Guizhou, Liao Guoping proposed the idea for regulation of the limit waterway dimension of stone shoal stream segments and determine a set of computation methods for waterway design dimensions combing the downstream of Chishui River.

\section{Maximum Navigable Dimension Which Duliu River May Achieve}

The rivers in mountain areas are with many curves and rapid flow. Therefore, the navigation width and bending radius determine navigation safety of the ships. Under the precondition of ensuring navigation safety, the problem of the maximum navigable dimension transforms to the possibility of improving the minimum design water depth (design water depth= design navigation depth + underkeel clearance). Under the condition of uniform flow, the design water depth is also influenced by the trenching longitudinal slope besides the trenching side slope and roughness coefficient. The smaller is the trenching longitudinal slope, the larger is the design water depth, and the smaller is the average flow velocity of the trenching section. When the average flow velocity of the trenching section is smaller than the local cobble starting flow velocity, in the stream segment which has covering layer of cobble, sedimentation will occur in the channel and the limit water depth increases. In the stream segment where bed rocks expose, such problems won't occur generally. The stream segments with covering layer of cobble of Duliu River are mainly in the stream segment above Rongyang Shoal.

There are many short and steep slope type dangerous shoals in Duliu River. At the end of the short and steep slope type dangerous shoal, the slope at the river bottom is steep, and the partial slope of water surface is large. Although the shoal segment distance is short, it is the crux river segment which controls the waterway regulation of the long stream segment. Even slight regulations of such dangerous shoals will cause relatively large fall of the water levels of the upstream and downstream stream segments; in the long slope type dangerous shoal, the river bottom slope is medium, and the distance is long. It is the ideal stream segment which can relieve the large fall of the water level after regulation of the downstream short and steep slope type dangerous shoal. At the same time, it is also the key stream segment to checkout whether the waterway dimension of the long stream segment after regulation can achieve the maximum reasonable value. Therefore, reasonable ascertaining of the river bottom longitudinal slopes of the short and steep slope type and the long slope type shoal segments after regulation, ensuring stable and sufficient navigation depth in the navigation channel and exploiting fully the navigation 
potential of the river course are the key technical problems which theoretical research needs to solve.

According to the ideas mentioned above, through the water power computation formula for uniform flow of open channels and the cobble starting flow velocity formula (when there is no cobble graduation material, the average flow velocity after the regulation should be slightly larger than the flow velocity before the regulation), the optimized and reasonable trenching section morphology of the dangerous shoal and the stable water depth and trench bottom longitudinal slope of the trenching can be deducted.

The formula for uniform flow of the open channel:

$$
Q=A V=A C \sqrt{R i}=\frac{1}{n} R^{1 / 6} A \sqrt{R i}=\frac{1}{n} A R^{2 / 3} i^{1 / 2}
$$

In the formula, $\mathrm{Q}$ is flow quantity $\left(\mathrm{m}^{3} / \mathrm{s}\right), \mathrm{V}$ is the average flow velocity of cross-section of flow $(\mathrm{m} / \mathrm{s}), A$ is the discharge area $\left(\mathrm{m}^{2}\right), C$ is the Chézy coefficient, $\mathrm{R}$ is the hydraulic radius $(\mathrm{m})$, and $\mathrm{i}$ is the river bottom longitudinal slope.

Formula of the discharge section area of trapezoid open channel:

$$
A=b h+m h^{2}
$$

In the formula: $A$ is the discharge area $\left(\mathrm{m}^{2}\right), \mathrm{b}$ is the bottom width $(\mathrm{m}), \mathrm{h}$ is the water depth $(\mathrm{m}), \mathrm{m}$ is the side slope coefficient.

Formula of hydraulic radius of the discharge section of the trapezoid open channel:

$$
R=A / \chi=A /\left(b+2 h \sqrt{1+m^{2}}\right)
$$

In the formula: $\chi$ is the wetted perimeter of the discharge section $(\mathrm{m})$.

Substitute the formula (3-2) and (3-3) into the formula (3-1), obtain the computation formulas for flow quantity and water depth of trapezoid trenching under uniform flow:

$$
Q=\frac{1}{n}\left(b h+m h^{2}\right)\left(\left(b h+m h^{2}\right) /\left(b+2 h \sqrt{1+m^{2}}\right)\right)^{2 / 3} i^{1 / 2}
$$

The formula of comprehensive roughness coefficient of compound trenching:

$$
n_{\text {综 }}==\sqrt{\frac{\chi_{1} n_{1}^{2}+\chi_{2} n_{2}^{2}+\chi_{3} n_{3}^{2}+\ldots+\chi_{k} n_{k}^{2}}{\chi_{1}+\chi_{2}+\chi_{3}+\ldots+\chi_{k}}}
$$

In the formula, $\chi_{k}$ is the subsection wetted perimeter of the discharge section, $n_{k}$ is the subsection roughness coefficient of the discharge section, and $\mathrm{k}$ is the number of subsections.

The formula of cobble starting flow velocity:

$$
V_{0}=4.4 d^{5 / 14} h^{1 / 7}
$$

Through computation, when the flow quantity $Q=60 \mathrm{~m}^{3} / \mathrm{s}$, the trenching bottom width $\mathrm{b}=15 \mathrm{~m}$, the trenching side slope 1:2 (i.e. side slope coefficient $\mathrm{m}=2$ ), the trench bottom longitudinal slope $\mathrm{i}$ $\approx 5 \%$. When the roughness coefficient is 0.030 according to the Tab.3, substitute the formula (3-4), obtain the water depth $\mathrm{h}=1.3 \mathrm{~m}$, and the average flow velocity $\mathrm{V}=2.62 \mathrm{~m} / \mathrm{s}$. Substitute the average flow velocity $\mathrm{V}=2.62 \mathrm{~m} / \mathrm{s}$ into the formula (3-6), obtain that the grain diameter of the starting cobbles is $0.21 \mathrm{~m}$, which is larger than the maximum starting grain diameter $0.20 \mathrm{~m}$. It shows that the above-mentioned trenching dimension and trench bottom longitudinal slope are of reasonable design and back-silting will not occur in the channel. It is the maximum reasonable waterway dimension under the design flow quantity of $60 \mathrm{~m}^{3} / \mathrm{s}$ which Duliu River may achieve after regulation.

The terrain of the mountain area river is complicated and changeable. The trenching section of some stream segment only needs partial trenching. In some partial stream segments with flow quantity above the design, combination of navigation-obstructing flow velocity and slope above the design will occur. The flow regime needs to be improved through compound trenching or cooperating with the regulation architectures. The roughness coefficient values of these stream segments will be complicated after regulation. The changed roughness coefficient can be calculated through the formula (4-10). 
Tab.3 Experience Roughness Coefficient Table

\begin{tabular}{lccc}
\hline \multicolumn{1}{c}{ Riverbed Characteristics } & \multicolumn{3}{c}{ Riverbed Status } \\
\cline { 2 - 4 } & Good & Common & Bad \\
\hline Detritus $d<50 \mathrm{~mm}$ & 0.020 & 0.025 & 0.030 \\
\hline Cobble $d=50 \sim 100 \mathrm{~mm}$ & 0.025 & 0.030 & 0.035 \\
\hline Big cobble $d=100 \sim 200 \mathrm{~mm}$ & 0.03 & 0.035 & 0.040 \\
\hline Hard rock $d>200 \mathrm{~mm}$ & 0.040 & 0.050 & 0.060 \\
\hline Rock block & 0.050 & 0.065 & 0.080 \\
\hline Large block of rock & 0.060 & 0.080 & 0.100 \\
\hline Stone plate & 0.050 & 0.060 & 0.070 \\
\hline Stone channel & 0.025 & 0.030 & 0.040 \\
\hline
\end{tabular}

\section{Conclusions}

Depending on the regulation project of the northern waterway of the access to the sea of southwest water transport, this article researches on the problem of the waterway dimension which the long stream segment regulation of Duliu River may achieve. Through the research, it proposes the computation method for the maximum navigable dimension, which is of great significance for guiding the improvement of the passing capacity of the long stream segment waterway.

\section{Acknowledgements}

This work was financially supported by National High Technology Research and Development Program 863 (2012AA112508), National Natural Science Foundation of China (51209112), and Basic research funding of national commonweal research institutions (TKS130202).

\section{References}

[1] East China Institute of Water Conservancy, Hydraulics, Science Press, 1983

[2]Guangxi Communications Planning Surveying and Designing Institute, Report on Prefeasibility Study of the Project of Northern Channel of the Access to the Sea of Southwest Water Transport, 2004, 4

[3]Guangxi Communications Planning Surveying and Designing Institute, Earlier Stage Geological Survey Report of the Project of Northern Channel of the Access to the Sea of Southwest Water Transport, 2004.3

[4]Zhou Guanlun, Rong Tianfu, Liu Shulun, Lu Hancai et al, Waterway Engineering Manual, People's Communications Press, 2003

[5]Min Chaobin, Research on Passing Capacity of the Waterway, Collected Works of Technical Communicating Meeting of Inland River Waterway Regulation Project, People's Communications Press, 1998.12

[6]Liao Guoping, Stone Shoal Regulation, Guizhou Education Press, 1997.12

[7] Zhou Lianyou, A Collection of Computation Formulas about Inland Waterway Dimension, Port Engineering Technology, 2004, (4): 7-10

[8]Copeland Ronald R, Hall Brad R. Channel restoration hydraulic design procedure. Proceedings of the ASCE Wetlands Engineering River Restoration Conference 1998. ASME, Fairfield, NJ, USA. 6p

[9]McCartney, Bruce L. Optimizing navigation channel dimensions. Proceedings of the Eighteenth Dredging Seminar. Texas A\&M University, Ocean Engineering Program (Report) COE n 284. Publ by Texas A\&M Univ, College Station, TX, USA p 13-20, 1985 